\title{
Overeducation e Undereducation no Brasil: Incidência e Retornos ${ }^{\star}$
}

\author{
- Maria Dolores Montoya Diaz * - Luciano Machado **
}

\begin{abstract}
RESUMO
Nos países desenvolvidos, a literatura acerca da sobreeducação encontra-se em expansão. Há vários autores preocupados com a existência de diferenças entre os requisitos educacionais das ocupações e a escolaridade possuída pelos indivíduos e os seus efeitos. $O$ objetivo deste artigo é acrescentar evidências a essa literatura, avaliando a incidência e os retornos da sobreeducação e da subeducação no Brasil, nas Grandes Regiões e no Estado de São Paulo. Também foram analisadas as diferenças por gênero e por grande grupo ocupacional. Foram utilizados dados do Censo de 2000 e da Classificação Brasileira das Ocupações de 2002. Entre as regiões, os níveis de adequação oscilaram entre $25 \%$ e $31 \%$ e os de sobreeducação entre $14 \%$ e 19\%. A região Sudeste apresentou a maior taxa de adequação e a região Sul a maior taxa de sobreeducação. O Nordeste apresentou a mais alta subeducação, sendo que quase $60 \%$ dos trabalhadores encontravam-se nesta condição. Relativamente aos retornos, a comparação entre os resultados de homens e mulheres evidenciou que o retorno de ser sobreeducada era de $13,9 \%$, enquanto o de ser sobreeducado era de $12,1 \%$. Verificamos, também, no caso dos homens, que o retorno da sobreeducação é maior nas regiões Centro-Oeste (I2,7\%) e Sudeste (I2,4\%). No caso das mulheres, constatamos que as duas regióes de maior dinamismo econômico - Sudeste e Sul - apresentaram menores retornos da sobreeducação (I3,6\% e I2, I\%, respectivamente).
\end{abstract}

\section{Palavras-Chave}

sobreeducação, subeducação, economia da educação, Brasil

\section{ABSTRACT}

The overeducation literature is increasing in developed countries. Several authors have estimated the education-occupation mismatch as well as its effects on individuals' earnings. The objective of this article is to add evidences to this literature, evaluating the incidence and the returns for overeducation and undereducation in Brazil, Regions and São Paulo State. We also focus on gender and occupational differences. Data is taken from Census 2000 and the Brazilian Occupational Titles (CBO) 2002. Regarding regional pattern, the proper-match level has oscillated between $25 \%$ and $31 \%$. The level of overeducation was between $14 \%$ and $19 \%$. The Southeast region presented the highest tax of proper-match and the South region presented the highest tax of overeducation. The Northeast region presented highest undereducation level (almost 60\%). As far as the returns are concerned, the return for women overeducated was $13.9 \%$, while the same rate for men was $12.1 \%$. The return for men overeducated was higher in Center-West (12.7\%) and Southeast (I2.4\%). The women overeducated return was lower in the two most dynamic regions: Southeast and South (13.6\% and $12.1 \%$, respectively).

\section{KEYWORDS}

overeducation, undereducation, economics of education, Brazil

\section{JEL CLASSIFICATION}

\section{$|2 I, J 3|$}

+ Este estudo foi financiado pela FAPESP e pelo CNPq. Os autores agradecem as valiosas sugestões, críticas e comentários de dois pareceristas anônimos da Estudos Econômicos, ressaltando, porém, que os erros e omissões eventualmente remanescentes são de nossa exclusiva responsabilidade.

* Departamento de Economia da FEA-RP/USP, Bolsista de Produtividade em Pesquisa do CNPq. E-mail: madmdiaz@ usp.br. Endereço para contato: Faculdade de Economia, Administração e Contabilidade de Ribeirão Preto - Universidade de São Paulo - Av. dos Bandeirantes, 3900 - CEP: I4049-900 - Ribeirão Preto - SP.

** Mestrando em Economia do Cedeplar-FACE-UFMG, Foi Bolsista de Iniciação Científica da FAPESP. e-mail: machado@cedeplar.ufmg.br. Endereço para contato: Av. Antônio Carlos, 6627. CEP: 31270-90I - Belo Horizonte-MG.

(Recebido em setembro de 2006. Aceito para publicação em maio de 2007). 


\section{$1 \quad$ INTRODUÇÃO}

A procura por níveis educacionais mais elevados tem sido observada em todo o mundo e, particularmente, no caso brasileiro, este movimento pode ser exemplificado pela expansão verificada no ensino médio e no superior. Em relação a este último nível, observou-se um acentuado incremento tanto no número de matrículas, que entre 1996 e 2005 aumentou mais de 138\%, como do número de concluintes, que no mesmo período cresceu aproximadamente $176 \%$. Ao discutir questões relativas a esse nível de ensino no Brasil, Schwartzman (2004) apresenta evidências de que os graduados podem não estar ocupando empregos para os quais têm se qualificado.

O crescimento dos níveis educacionais da população foi ponto de partida para uma literatura em expansão que procura avaliar as possibilidades e as condições em que esta oferta adicional de qualificação, medida em termos educacionais, está sendo absorvida pelo mercado de trabalho.

Dessa forma, verificou-se, por um lado, a existência de indivíduos que ocupavam posições que não exigiam a escolaridade possuída, que denominaremos sobreeducados, e, por outro, indivíduos que possuíam menos escolaridade que a requerida pela ocupação, os subeducados. Há, ainda, indivíduos que possuem exatamente a escolaridade requerida para a atividade desempenhada, que classificaremos como adequados.

A existência de sobreeducação levanta questões interessantes acerca das teorias existentes sobre a dinâmica do mercado de trabalho e sobre sua ligação com o sistema educacional.

De acordo com McGuinness (2006), em resenha sobre o tema da sobreeducação, até este momento não há uma teoria unificadora aceita acerca do fenômeno da sobreeducação. Na verdade, o fenômeno tem sido interpretado na literatura especializada dentro de três perspectivas sobre o mercado de trabalho: Teoria do Capital Humano, Modelo de Competição por Emprego ${ }^{1}$ e Assignment Models.

A compatibilidade entre a existência de sobreeducação e a Teoria do Capital Humano pode ser defendida com base no argumento da transitoriedade da situação, com duração determinada pelo tempo que o trabalhador demoraria a encontrar um trabalho mais adequado a seu potencial ou pelo tempo necessário para as firmas poderem promover um ajustamento dos processos produtivos para adequá-los à utilização plena do capital humano disponível. Outra linha de defesa da adequação entre a sobreeducação e a Teoria do Capital Humano é a de que a escolaridade adicional

1 Job Competition Model. 
estaria apenas compensando a falta de capacitação nas empresas (on-the-job training), e/ou algum grau de inferioridade em termos de habilidades para a realização das atividades exercidas. Nesta mesma linha, a subeducação poderia ser explicada pela experiência ou pela formação no próprio trabalho.

Sendo assim, McGuinness (2006) prossegue argumentando que a inconsistência da Teoria do Capital Humano, dada a existência de sobreeducação, seria defensável apenas se fosse possível comprovar que a sobreeducação é um fenômeno de longo prazo e/ou persistente quando são incluídos todos os controles, por exemplo, relativos aos investimentos em capital humano realizados nas firmas e à heterogeneidade das distintas habilidades dos trabalhadores.

Seguindo McGuinness (2006), o Modelo de Competição por Emprego fornece uma clara explicação teórica para o fenômeno da sobreeducação na medida em que se fundamenta na premissa de que os indivíduos competem pelas oportunidades de emprego baseando-se nos seus custos relativos de treinamento, e não na remuneração que estariam dispostos a aceitar dado seu nível de escolaridade. Deste modo, quanto maior for o número de indivíduos educados na população maior será a necessidade individual de investir em educação como forma de preservar sua posição.

Finalmente, de acordo com Hartog (2000), a sobreeducação também seria consistente com a interpretação gerada pelos Assignment Models, na medida em que nestes modelos é explícita a relevância do lado da demanda no mercado de trabalho. Deste modo, a aferição da qualidade do "vínculo" entre postos de trabalho e trabalhadores estaria na mesma linha de análise da "designação" de trabalhadores heterogêneos a postos heterogêneos. Estes modelos contemplam a possibilidade de existirem pontos de equilíbrio em que as alocações entre o nível de atributos do trabalhador e os atributos exigidos para o posto envolvam algum grau de desvio. Desta forma, alguns destes desvios seriam pontos de ocorrência de sobre ou subeducação.

Relativamente à metodologia utilizada para tratar do tema, verifica-se que Duncan e Hoffman (1981) foram os pioneiros na tentativa de estimar os impactos sobre os rendimentos da sobreeducação e da subeducação, distinguindo na função de rendimentos minceriana a escolaridade requerida no emprego da escolaridade possuída pelo indivíduo, introduzindo, assim, a função de rendimentos padrão utilizada na literatura (ORU).

Hartog (2000) compara estudos de cinco países (EUA, Holanda, Portugal, Espanha e Reino Unido), num intervalo de duas décadas, evidenciando regularidades na incidência da sobreeducação e subeducação. Com exceção dos EUA e Portugal, para os 
quais a incidência de adequados era inferior, verificou-se que, em média, 60\% da força de trabalho ocupava empregos apropriados para sua formação educacional.

As regularidades podem ser mostradas também com respeito às conseqüências sobre os rendimentos, avaliadas pela função padrão adotada na literatura de sobreeducação. Conforme resumido em Hartog (2000):

1. os retornos da escolaridade requerida no emprego são superiores aos retornos da escolaridade possuída pelo indivíduo. Isto segue de uma comparação entre o modelo padrão de Mincer (1974) e o modelo padrão da literatura (DUNCAN; HOFFMAN, 1981; RUMBERGER, 1987).

2. os retornos são positivos para sobreeducação, todavia menores do que os da escolaridade requerida. Em geral, em torno de metade a dois terços do retorno desta última.

3. os retornos da subeducação são negativos e menores do que os retornos para educação requerida. É comum serem também menores do que os retornos para sobreeducação.

Estas regularidades indicam, deste modo, que em um dado posto de trabalho associado a um determinado nível de educação requerida o rendimento dos sobreeducados (subeducados) será, em média, superior (inferior) àquele auferido pelos trabalhadores que possuem exatamente o nível de escolaridade requerido. Porém, é preciso notar que um trabalhador sobreeducado terá, em média, rendimentos menores do que aqueles recebidos por trabalhadores que possuem seu nível de escolaridade, mas ocupam postos em que há equivalência entre escolaridade requerida e a possuída (retorno da sobreeducação é positivo, porém, menor do que o da escolaridade requerida). Adicionalmente, a terceira delas indica que a subeducação é menos penalizada do que a sobreeducação é recompensada.

É interessante notar, também, a escassez de estudos dessa natureza em países em desenvolvimento. Quinn e Rubb (2006) apontam esse fato e calculam a incidência e os efeitos da sobreeducação e subeducação a partir de dados do mercado de trabalho do México, procurando investigar se as regularidades encontradas nos países desenvolvidos se mantêm neste país.

Para o Brasil, esse tema foi tratado por Santos (2002), que procurou verificar a incidência e o prêmio para sobreeducação nos anos de 1992, 1995, 1997 e 1999, a partir dos dados da PNAD, considerando apenas 24 categorias profissionais e utilizando 
uma metodologia mais limitada, como decorrência das restrições existentes na base de dados utilizada pelo autor.

Finalmente, é importante destacar que a existência da sobreeducação pode ser custosa para indivíduos, firmas e para a toda a economia. Como esclarece McGuinness (2006), em nível macroeconômico a existência de sobreeducação pode significar que a economia está operando em um ponto cujo nível de bem-estar é potencialmente inferior ao atingido na situação em que todas as habilidades dos sobreeducados fossem plenamente utilizadas, ou, pode também implicar que recursos estejam sendo desperdiçados na medida em que estariam alocados no fornecimento de uma formação e/ou educação não produtiva. Para as firmas, o autor menciona a existência de algumas evidências, sugerindo que a sobreeducação estaria associada com uma baixa produtividade e que os indivíduos sobreeducados tenderiam a apresentar menores níveis de satisfação no trabalho, além do caso das minorias, que tenderiam a ser mais afetadas pelo fenômeno.

Justamente por estas razões e pelo fato de que, até este momento, à exceção do trabalho de Santos (2002), a análise da sobreeducação não ter recebido maior atenção na literatura especializada brasileira, busca-se aqui acrescentar evidências a este debate, avaliando a incidência e os efeitos sobre os rendimentos da diferença entre escolaridade requerida na ocupação e escolaridade possuída pelo indivíduo, especialmente com desagregação regional, para o Estado de São Paulo, maior mercado de trabalho entre os Estados brasileiros, e para as Grandes Regiões, por gênero e por grupos de ocupações.

Para tanto, aplica-se a metodologia de Job Analysis, considerada a mais adequada para este tipo de análise por Hartog (2000) e Verhaest e Omey (2006), para o cálculo da incidência dos fenômenos, e são estimadas diversas funções $O R U^{2}$ para mensuração dos retornos para a educação requerida, sobreeducação e subeducação, o que distingue este trabalho daquele elaborado por Santos (2002). Para esse fim, são utilizados dados do Censo de 2000 e as descrições contidas na Classificação Brasileira das Ocupações (CBO) de 2002.

A próxima seção é dedicada à apresentação da metodologia e das bases de dados utilizados. Na seção três são expostos os resultados encontrados com relação às medidas de sobreeducação e subeducação e aos modelos estimados. A última seção traz as conclusões do trabalho e compara os resultados brasileiros com os de outros países.

2 Função relativa à estimação de sobreeducação, escolaridade requerida e de subeducação - ORU é Overeducation, Required e Undereducation. 


\section{METODOLOGIA E VARIÁVEIS UTILIZADAS}

\subsection{Aspectos Teóricos}

De acordo com a literatura existente nesse tema, define-se sobreeducação como sendo a escolaridade possuída pelo indivíduo maior que a requerida pela sua ocupação; subeducação, de modo inverso, corresponde à situação em que a escolaridade requerida é maior que a possuída pelo indivíduo.

Rubb (2005) procura enfatizar a existência de uma sutil diferença entre os conceitos de sobreeducação e de subemprego, que representaria a situação em que o trabalhador desempenharia atividades que requereriam um nível de escolaridade menor do que aquele possuído. Essencialmente, a diferença consistiria no fato de que para avaliar o subemprego seria necessário comparar a ocupação de indivíduos com a mesma escolaridade. Assim, o controle se faria pela escolaridade e não pela ocupação.

Sendo assim, consideraremos sobreeducado o indivíduo que possuir mais escolaridade do que é exigido na ocupação em que se encontra, ou seja, controlada a ocupação, verifica-se se o nível de escolaridade do indivíduo é maior, igual (adequado) ou menor (subeducado) do que aquele exigido para a respectiva ocupação.

A escolaridade requerida para uma determinada ocupação tem sido determinada basicamente por três métodos diferentes na literatura. O primeiro corresponde à job analysis (JA), que adota a definição de escolaridade requerida tendo por fundamento uma classificação feita por analistas de emprego profissionais, que codificam as ocupações no mercado de trabalho, especificando a formação escolar adequada para cada uma. O segundo método é o worker self-assessment, no qual a escolaridade requerida baseia-se na informação fornecida pelo próprio trabalhador; no terceiro, realized matches, a escolaridade requerida é obtida a partir da média ou moda da distribuição da escolaridade efetiva dos trabalhadores analisados. Este último foi o procedimento adotado por Santos (2002).

Hartog (2000) considerou o método job analysis conceitualmente superior, na avaliação dos méritos relativos das três medidas analisadas. Verhaest e Omey (2006) realizaram uma análise comparativa entre cinco medidas alternativas de sobreeducação: job analysis; avaliação dos trabalhadores sobre a escolaridade requerida para realizar o trabalho (worker-assessment of the required level to do the job); avaliação dos trabalhadores sobre a escolaridade requerida para obter o trabalho (worker-assessment of the required level to get the job); nível educacional médio e nível educacional modal. Os autores concluíram que para nenhuma das quatro variáveis de resultado avaliadas 
(salários, satisfação no trabalho, mobilidade e participação em treinamento) o método job analysis foi superado por qualquer das outras quatro alternativas.

É importante ressaltar que esta metodologia também pode apresentar algumas limitações. A primeira delas refere-se à possibilidade mencionada por Verhaest e Omey (2006) sobre o risco de ocorrência de erros aleatórios na mensuração da escolaridade requerida bem como na classificação das ocupações, dependendo da forma como as atividades dos especialistas tenham sido realizadas. Outra possível limitação está relacionada à pouca freqüência das atualizações das tabelas de classificação de ocupações como decorrência da complexidade e dos elevados custos envolvidos na elaboração deste tipo de trabalho. Deste modo, o acompanhamento de longo prazo do fenômeno da sobreeducação fica comprometido, pois a dinâmica do mercado de trabalho pode provocar modificações profundas nas exigências educacionais para o desempenho de diversas atividades, tornando obsoletas as informaçóes constantes das tabelas de ocupações.

Sendo assim, será adotado neste estudo o método job analysis, pois além das vantagens mencionadas anteriormente, verifica-se, no caso brasileiro, também uma grande proximidade em relação às bases de dados utilizadas, visto que a classificação de ocupações é de 2002 e os dados dos indivíduos datam do ano 2000. Com isso, espera-se que parte importante das limitações mencionadas esteja sob controle.

No Brasil, a Classificação Brasileira das Ocupações (CBO) é responsável pela codificação das ocupações no mercado de trabalho. Assim, por meio da CBO de 2002, verificar-se-á a escolaridade requerida de cada família ocupacional escolhida, o que é fundamental para que se possa proceder às análises propostas.

\subsection{Função de Rendimentos ORU ${ }^{3}$}

A função de rendimentos utilizada para obter estimativas de sobreeducação ${ }^{4}$ e de subeducação é a seguinte:

$$
\ln W=\alpha_{1}+\beta_{r} S_{r}+\beta_{o} S_{o}+\beta_{u} S_{u}+\delta_{1} \Phi_{1}+\varepsilon
$$

onde $S_{r}$ são anos de escolaridade requerida para uma família ocupacional específica, $S_{o}$ é o número de anos de escolaridade do indivíduo a mais do que é requerido para

3 Over-, Required e Undereducation.

4 Apesar de a maioria dos trabalhos na área adotarem este modelo, esta não é a única função utilizada para medir os impactos nos rendimentos de sobreeducação e subeducação. Um outro exemplo pode ser visto em Rubb (2003). 
o emprego e $S_{u}$ é o número de anos de escolaridade do indivíduo a menos do que é requerido para o emprego. $\Phi_{1}$ é um vetor de outras variáveis de controle, que geralmente incluem experiência, $\alpha_{1}$ é o intercepto e $\varepsilon$ é o termo aleatório.

Neste estudo, adota-se a seguinte função, que segue o padrão de especificação do modelo acima:

$\ln s a l / h=\alpha_{1}+\beta_{1}$ sobreduc $+\beta_{2}$ escolar_requer $+\beta_{3}$ subeduc $+\delta_{1}$ idade $+\delta_{2}$ idade_quad $+\varepsilon$

onde $\ln \mathrm{sal} / \mathrm{h}$ é o logaritmo natural dos salários mensais por hora ${ }^{5}$, idade é a idade do indivíduo, idade_quad é o valor desta ao quadrado, sobreduc é o número de anos de sobreeducação do indivíduo, escolar_requer é o valor da escolaridade requerida para uma dada família ocupacional, subeduc é o número de anos de subeducação do indivíduo, $\alpha_{1}$ é o intercepto e $\varepsilon$ é o termo aleatório. De acordo com a literatura, com relação à definição das variáveis, tem-se:

- escolar_possuída : anos de estudo que o indivíduo possui ${ }^{6}$

- $\quad$ sobreduc $=$ escolar_possuída - escolar_requer se a primeira for maior que a segunda, sendo zero para os demais casos

- $\quad$ subeduc = escolar_requer - escolar_possuida se a primeira for maior que a segunda, sendo zero para os demais casos

A partir dessa função poderá ser avaliado o impacto sobre os rendimentos de estar adequado com relação aos requerimentos educacionais, isto é, possuir o mesmo número de anos de estudo requerido na ocupação (coeficiente da variável escolaridade requerida) e de possuir anos de estudo a mais (coeficiente da variável sobreeducação) ou a menos (coeficiente da variável subeducação) do exigido para uma dada família ocupacional. $^{7}$

5 Há diversas variáveis de rendimentos no Censo 2000. Como o código da ocupação se refere ao trabalho principal, utilizaram-se as variáveis de salário e total de horas trabalhadas por semana referentes a este. As variáveis usadas são: V4513 - total de rendimentos no trabalho principal e V0453 - horas trabalhadas por semana no trabalho principal. Logo, a variável salário por hora é obtida pela divisão de V4513 por V0453. Portanto, utilizou-se o salário por hora semanal do indivíduo.

6 Variável V4300 no censo. O valor 17 dessa variável representa 17 anos ou mais de estudo. Nos modelos considera-se como sendo apenas 17 anos.

7 É fundamental destacar a importância para o tratamento deste tema dos debates acerca do papel das habilidades individuais na determinação tanto da remuneração como do nível de escolaridade, ou seja, do problema da endogeneidade dos regressores. A este respeito, McGuinness (2006) não apresenta 


\subsection{Bases de Dados}

Foram utilizados os dados do Censo de $2000^{8}$ retirados do banco de indivíduos, relativos aos domicílios que responderam ao questionário mais detalhado ${ }^{9}$, juntamente com a Classificação Brasileira das Ocupações domiciliar e as descrições da Classificação Brasileira das Ocupações de 2002.

A nova versão desta classificação apresenta as ocupações do mercado de trabalho brasileiro organizadas e descritas por famílias ocupacionais. ${ }^{10} \mathrm{E}$ importante notar que "cada familia constitui um conjunto de ocupaçóes similares correspondente a um domínio de trabalho mais amplo que aquele da ocupação." 11

Os grandes grupos agregam as famílias ocupacionais por nível de competência e similaridade nas atividades executadas e encontram-se descritos no quadro a seguir.

evidências conclusivas. Por um lado, menciona três artigos que procuraram controlar os efeitos das habilidades heterogêneas dos trabalhadores e acabaram concluindo que quando se considera explicitamente este aspecto os diferenciais salariais decorrentes da sobreeducação tendem a desaparecer. Por outro lado, o próprio McGuinness (2006) critica estes trabalhos por assumirem que todas as diferenças individuais não-observáveis relacionam-se somente com habilidades, ignorando, conseqüentemente, o impacto de outras características pessoais e do posto de trabalho, e comprometendo os resultados encontrados por um potencial viés de omissão de variável relevante. Nesta direção, cita resultados obtidos por McGuinness e Bennett (2006) que, ao utilizar técnicas de regressão quantílica para controlar heterogeneidade nas habilidades não-observadas, encontraram efeitos estatisticamente significativos da sobreeducação tanto para homens com habilidade média e baixa como para mulheres de todos os níveis de habilidade.

8 É importante notar, conforme consta da documentação do Censo de 2000 que trata de aspectos da amostragem: "Na coleta das informações do Censo 2000, foram usados dois modelos de questionário: 1. um questionário básico aplicado nas unidades não selecionadas para a amostra e contendo perguntas referentes às caracteristicas que foram investigadas para $100 \%$ da população; 2 . um segundo questionário aplicado somente nos domicílios selecionados para a amostra contendo, além das perguntas que também constam do questionário básico, outras perguntas mais detalhadas sobre caracteristicas do domicilio e de seus moradores, referentes aos temas religião, cor ou raça, deficiência, migração, escolaridade, fecundidade, nupcialidade, trabalho e rendimento. Em todo o território nacional foram selecionados 5.304.711 domicilios para responder ao questionário da amostra, o que significon uma fração amostral da ordem de 11,7\%. Nesses domicilios foram levantadas as informaçôes para todos os seus moradores, totalizando 20.274 .412 pessoas."

9 Por esta razão, todas as estimações realizadas foram ponderadas pela variável peso também fornecida pelo IBGE.

10 Por exemplo, o código 3222 na CBO 2002 refere-se à família ocupacional dos Técnicos de Enfermagem, que engloba duas ocupações: técnicos de enfermagem, para os quais exige-se nível médio de ensino, e auxiliares de enfermagem, para os quais exige-se ensino fundamental completo.

11 Definição contida no livro 1 da Classificação Brasileira das Ocupações de 2002. 


\section{QUADRO I - GRANDES GRUPOS NA CBO 2002}

\section{GG - Título do grande grupo}

0 - Forças Armadas, Policiais e Bombeiros Militares

1 - Membros superiores do poder público, dirigentes de organizações de interesse público e de empresas e gerentes

2 - Profissionais das ciências e das artes

3 - Técnicos de nível médio

4 - Trabalhadores de serviços administrativos

5 - Trabalhadores dos serviços, vendedores do comércio em lojas e mercados

6 - Trabalhadores agropecuários, florestais, da caça e pesca

7 - Trabalhadores da produção de bens e serviços industriais ${ }^{12}$

8 - Trabalhadores da produção de bens e serviços industriais ${ }^{13}$

9 - Trabalhadores de manutenção e reparação

Os indivíduos no Censo têm sua ocupação codificada segundo a família ocupacional a que esta pertence. Há algumas implicações desse fato para a análise, pois uma família ocupacional específica pode conter diversas ocupações associadas a diferentes níveis de escolaridade requerida, o que dificulta, a princípio, a determinação desse dado, que é a base para o cálculo da incidência de sobreeducação e subeducação.

É importante observar que o termo ocupação foi usado como sendo o foco da análise da diferença entre escolaridade requerida e escolaridade possuída. Entretanto, ao utilizar a Classificação Brasileira das Ocupações como instrumento de avaliação, é preciso notar a distinção dos conceitos de família ocupacional e ocupação. Dessa forma, adotou-se o termo ocupação por simplicidade, mas o conceito a que se refere é o da família ocupacional. Logo, a análise da diferença é feita tendo como base as informações sobre escolaridade requerida contidas na descrição de cada família ocupacional, a qual se aplica às ocupações incluídas na família. Como os códigos atribuídos às ocupaçóes dos indivíduos no Censo de 2000 se referem às famílias ocupacionais, objetiva-se determinar uma escolaridade requerida para cada família analisada, a fim de poder determinar a escolaridade requerida para cada indivíduo.

Outro ponto relevante é o fato de que, à época da realização do Censo de 2000, a nova versão da Classificação Brasileira das Ocupações ainda não estava pronta, o

12 No GG 7 foram agrupados os trabalhadores de sistemas de produção que tendem a ser discretos e que lidam mais com a forma do produto do que com o seu conteúdo físico-químico.

13 No GG 8 agruparam-se os trabalhadores de sistemas de produção que são ou tendem a ser contínuos (química, siderurgia, dentre outros). 
que resultou no uso de uma classificação provisória - CBO domiciliar - para a codificação das famílias ocupacionais. Contudo, esta já estava enquadrada nos padrões reformulados da nova classificação, que só foi publicada em 2002.

\subsection{Seleção de Dados}

Inicialmente, de posse dos dados de pessoas do Estado de São Paulo, passou-se à definição das famílias ocupacionais a serem analisadas. Posto que o número de famílias ocupacionais era vasto (508), optou-se por analisar mais profundamente uma quantidade menor de famílias, por grande grupo.

Após obter os dados do número de indivíduos por família ocupacional, calculou-se o número médio de empregados dentro de cada grande grupo. As famílias que apresentaram número de ocupantes acima desta média foram selecionadas para compor a base de dados a ser analisada, resultando num total de 103 famílias ocupacionais.

É necessário ressaltar que, dos dez grandes grupos da Classificação Brasileira das Ocupações, dois não foram considerados neste estudo - grande grupo zero e grande grupo um, pelo fato de não ser possível a determinação de um nível de escolaridade requerida para a maioria das famílias devido às características das ocupações inseridas nesses grandes grupos. ${ }^{14}$

Após a seleção das famílias ocupacionais, foram elaboradas as tabelas com a frequiência de indivíduos por ano de estudo para cada família ocupacional. De posse destas, passou-se à determinação da escolaridade requerida das famílias, por meio de consulta à Classificação Brasileira das Ocupações de 2002, que consistiu em:

1) Dado o código da família ocupacional na CBO domiciliar, verificou-se a existência desse código na Classificação Brasileira das Ocupações de 2002 e se a família ocupacional era a mesma (caso que se repetiu na maioria das averiguações). Se não existia o código ou caso um mesmo código se referisse a duas famílias distintas, investigava-se se esta família ocupacional estava incluída na classificação de 2002, para que se pudesse determinar o nível de escolaridade requerida da família ocupacional.

14 Comparando a média do salário por hora, observa-se que esta é de R \$ 3,23 entre todos os indivíduos ocupados nos grandes grupos 2 a 9, é de R \$,60 entre os indivíduos incluídos na amostra e é de R \$ 10,39 para os grandes grupos 0 e 1 , bem superior aos demais valores, o que se justifica pelas famílias ocupacionais que estão inseridas nestes grandes grupos. Verifica-se, também, que entre todos os indivíduos ocupados nos grandes grupos 2 a 9 é de 6,9 a média de anos de estudo. Entre os indivíduos incluídos na amostra é de 7,6 anos de estudo o valor médio encontrado, e é 9,9 a referida média para os indivíduos pertencentes aos GG 0 e GGl. 
2) Caso a classificação de 2002 contivesse a família ocupacional, partia-se para a determinação da escolaridade requerida, a qual estava contida na ficha de descrição da família. Na seção "Formação e Experiência", é descrita a exigência com respeito aos anos de estudo e experiência necessários para que o indivíduo possa desempenhar suas funções na família ocupacional. Neste estudo é relevante apenas a descrição da escolaridade exigida, a qual é traduzida em anos de estudo requeridos para a família ocupacional.

Nesse processo foi necessária, ainda, a eliminação de algumas famílias selecionadas para a análise devido à falta de similares na Classificação Brasileira das Ocupações de $2002^{15}$ ou por não ser requerida escolaridade formal para o desempenho das ocupações. ${ }^{16}$ Ocorreram alguns casos em que as famílias apresentavam formação exigida sobremodo diversa dos ocupantes e até mesmo a não-exigência de escolaridade formal para algumas das ocupações, devido ao abrangente número destas na família ${ }^{17}$, o que impossibilitava a determinação da escolaridade requerida.

Por conseguinte, pode-se notar que a Classificação Brasileira das Ocupações de 2002 permitiu a avaliação da quase totalidade de famílias ocupacionais selecionadas devido à semelhança com a classificação domiciliar. Apenas cinco das 103 famílias não tiveram similares na classificação de 2002. As outras 14 famílias que foram excluídas, em sua maioria, não possibilitavam a determinação da escolaridade requerida devido à diversidade de ocupações que compunham as mesmas. Logo, as análises basearamse num total de 84 famílias ocupacionais, conforme constam da tabela a seguir: ${ }^{18}$

15 Condutores e Operadores Polivalentes - 7820, Técnicos Esportivos - 3771, Técnicos e Fiscais de Tributação e Arrecadação - 3515, Outros Trabalhadores Elementares Industriais - 8711 e Secretários de Expediente e Estenógrafos - 4121 .

16 Produtores Agrícolas - 6129, Instrutores e Professores de Escolas Livres - 3331, Trabalhadores Artesanais de Materiais de Construção - 8281, Trabalhadores de Cargas e Descargas de Mercadorias 7832 e Trabalhadores Agrícolas - 6229. Devido às exclusões de duas famílias do grande grupo 6, este ficou com apenas uma família ocupacional na análise.

17 Trabalhadores nos Serviços de Higiene e Embelezamento - 5161, Técnicos em Operação de Computadores - 3172, Garçons, Barmen e Copeiros - 5134, Outros Trabalhadores dos Serviços 5199, Trabalhadores nos Serviços de Manutenção e Conservação de Edifícios e Logradouros - 5142, Ministros de cultos religiosos, missionários e afins - 2631, Desenhistas industriais (Designer), escultores, pintores e afins - 2625, Professores e instrutores do Ensino Profissional - 2330 e Compositores, Músicos e Cantores - 2624.

18 Os indivíduos selecionados para compor a base de dados do estudo (84 famílias ocupacionais contidas nos grandes grupos de 2 a 9) correspondem a $20,2 \%$ da população brasileira naquele ano, e $38,6 \%$ dos brasileiros estavam ocupados na data de realização do censo. A proporção de indivíduos nos grandes grupos de interesse - grandes grupos 2 a 9 - é de 36,1\% da população total. Dentre os indivíduos ocupados, nota-se que $52,32 \%$ estão nas famílias ocupacionais selecionadas para o estudo. A proporção dos ocupados que se encontram nos grandes grupos 0 e 1 , que não são considerados na análise, é de 6,6\%. Já nos grandes grupos de 2 a 9 está a grande maioria dos ocupados, 93,4 \%. Considerando apenas o universo formado pelos indivíduos ocupados nos grandes grupos de 2 a 9 , a proporção de indivíduos selecionados para o estudo é de $56 \%$. 


\section{TABELA 1 - TOTAL DE FAMÍLIAS OCUPACIONAIS SELECIONADAS POR GRANDE GRUPO}

\begin{tabular}{ccc}
\hline Grande Grupo & Número de famílias ocupacionais & Número de famílias selecionadas \\
\hline 2 & 77 & 20 \\
3 & 112 & 22 \\
4 & 22 & 5 \\
5 & 36 & 6 \\
6 & 13 & 1 \\
7 & 133 & 20 \\
8 & 53 & 4 \\
9 & 33 & 6 \\
Total & 479 & 84 \\
\hline
\end{tabular}

Um aspecto importante a ser ressaltado relativamente ao conjunto de dados selecionados refere-se à proporção do mercado de trabalho formal incluída na análise. $\mathrm{Na}$ Tabela 2, observa-se que a porcentagem de empregados com carteira de trabalho assinada é similar para o total de ocupados e para as famílias ocupacionais selecionadas $-34,19$ e 35,21 por cento, respectivamente. O mesmo pode ser dito com respeito à porcentagem de empregados sem carteira de trabalho assinada $(24,31$ e 24,33 por cento para o total de ocupados e para as famílias ocupacionais selecionadas, respectivamente). Outra categoria com porcentagem similar é a dos trabalhadores por conta própria, 23,46 e 23,18 por cento para o total de ocupados e para as famílias ocupacionais selecionadas, respectivamente. Portanto, percebe-se que a distribuição dos indivíduos na base de dados do estudo e na base de dados com o total de ocupados é muito semelhante com respeito ao grau de formalização do mercado de trabalho. 
TABELA 2 - DISTRIBUIÇÃO DOS TRABALHADORES SEGUNDO A POSIÇÃO NA OCUPAÇÃO

\begin{tabular}{l|cc}
\hline Posição na ocupação & $\begin{array}{c}\text { Total de ocupados } \\
\%\end{array}$ & $\begin{array}{c}\text { Amostra do estudo } \\
\%\end{array}$ \\
\hline 1- trabalhador doméstico com carteira de trabalho assinada & 2,27 & 4,22 \\
2 - trabalhador doméstico sem carteira de trabalho assinada & 5,37 & 9,80 \\
3 - empregado com carteira de trabalho assinada & 34,19 & 35,21 \\
4 - empregado sem carteira de trabalho assinada & 24,31 & 24,33 \\
5 - empregador & 2,89 & 1,10 \\
6 - conta própria & 23,46 & 23,18 \\
7 - aprendiz ou estagiário sem remuneração & 0,44 & 0,47 \\
8 - não remunerado em ajuda a membro do domicílio & 3,97 & 1,69 \\
9 - trabalhador na produção para o próprio consumo & 3,10 & 100,00 \\
\hline
\end{tabular}

Outros dois aspectos a serem destacados relativamente à amostra referem-se à proporção da amostra por região e por gênero. Na Tabela 3, verifica-se que, considerando apenas os ocupados nos grandes grupos de 2 a 9 , a proporção de indivíduos selecionados é maior no Sudeste $(61,24 \%)$, seguido pelo Centro-Oeste $(61,15 \%)$.

TABELA 3 - PROPORÇÃO DA AMOSTRA POR REGIÃO

\begin{tabular}{l|cccccc}
\hline Amostras & $\begin{array}{c}\text { Norte } \\
\%\end{array}$ & $\begin{array}{c}\text { Nordeste } \\
\%\end{array}$ & $\begin{array}{c}\text { Sudeste } \\
\%\end{array}$ & $\begin{array}{c}\text { Sul } \\
\%\end{array}$ & $\begin{array}{c}\text { Centro-Oeste } \\
\%\end{array}$ & $\begin{array}{c}\text { Brasil } \\
\%\end{array}$ \\
\hline Amostra do estudo & 50,99 & 48,10 & 61,24 & 53,96 & 61,15 & 56,00 \\
$\begin{array}{l}\text { Total de ocupados - } \\
\text { GG 2 a 9 }\end{array}$ & 100,00 & 100,00 & 100,00 & 100,00 & 100,00 & 100,00 \\
\hline
\end{tabular}

A proporção da amostra por gênero mostra que, entre os homens, esta representa $52,22 \%$ dos indivíduos ocupados nos grandes grupos de 2 a 9 e entre as mulheres a referida proporção é de $62,04 \%$.

Deste modo, nota-se a grande dimensão da amostra (superior a $48 \%$ do universo, no caso da distinção geográfica, e de $52 \%$, no caso da distinção por gênero). Consideramos, assim, que problemas decorrentes da eventual presença de algum viés de seleção estão sob controle. 


\subsection{Determinação da Escolaridade Requerida}

Houve dois tipos de situações na determinação da escolaridade requerida. Aquela em que a escolaridade requerida para a família ocupacional era única e aquela em que a mesma englobava mais de um ano. A primeira ocorria quando todas as ocupações contidas na família exigiam a mesma escolaridade requerida ou quando a maioria das ocupações exigia uma mesma escolaridade. Quando isto não acontecia, isto é, não havia uma única escolaridade exigida para toda a família e era impossível determinar uma maioria, partiu-se para o uso de faixas de escolaridade requerida, ou seja, a escolaridade requerida seria uma faixa que englobasse as exigências de escolaridade das ocupações da família.

No caso dos Técnicos e Auxiliares de Enfermagem, por exemplo, para determinar a escolaridade exigida construiu-se uma faixa que engloba as exigências de escolaridade de cada ocupação contida na família, a qual começa nos oito e vai até os onze anos de estudo. Ressalta-se que houve casos em que todas as ocupações de uma família exigiam a mesma escolaridade, todavia a escolaridade requerida para a família compreendia uma faixa de escolaridade. ${ }^{19}$

Para o grande grupo 2 (profissionais das ciências e das artes), a escolaridade requerida foi determinada utilizando a Classificação Brasileira das Ocupações de 2002 e o Manual da Fuvest de 2000, que permitia a quantificação em anos de estudo da escolaridade exigida, a qual era descrita na CBO como o curso ou gama de cursos de nível superior requeridos para o desempenho das ocupações relacionadas.

Dessa forma, consultou-se o Manual para verificar o tempo de duração das carreiras de graduação descritas em cada família e, assim, determinar a exigência da família ocupacional em anos de estudo. Quando havia mais de um período de duração das carreiras, definiram-se como anos de estudo necessários para conclusão da carreira os anos que correspondessem a todas as opções de duração dos cursos. Por exemplo, cursos oferecidos em turnos distintos muitas vezes têm durações diferentes (o curso de Economia no Manual da Fuvest aparece para o período diurno com duração de oito semestres e para o noturno com duração de dez semestres), logo, a família ocupacional que exigisse a graduação em Economia tem como escolaridade requerida uma faixa que compreende duas escolaridades - 15 e 16 anos de estudo -, ou seja, considera-se que o indivíduo que está empregado possa advir de uma graduação freqüientada em curso diurno ou em curso noturno. Portanto, nesse grande grupo,

19 As faixas de escolaridade são usadas na minoria das famílias ocupacionais selecionadas $(34,5 \%$, ou seja, 29 famílias). Deste modo, temos 55 famílias ocupacionais que apresentam escolaridade requerida contendo apenas um único ano de estudo $(65,5 \%)$. Com respeito à amplitude das faixas, entendida como sendo a diferença entre o maior valor da faixa e o menor valor da mesma, a média foi de aproximadamente dois anos e meio. 
apesar de a maioria das famílias exigir uma mesma escolaridade para todas as ocupações, esta não é necessariamente uma escolaridade única, pois pode englobar mais de um ano de estudo. ${ }^{20}$

Posto isso, após haver determinado a escolaridade requerida para uma dada família ocupacional, calcula-se a porcentagem de trabalhadores que estão adequados na família. Para isso, divide-se o total de indivíduos que possuem o número de anos de estudo exigidos, segundo a Classificação Brasileira das Ocupações de 2002, pelo total de indivíduos que se encontram na família. A porcentagem de indivíduos que possuem menos que a escolaridade requerida é a proporção de subeducação e a porcentagem dos mesmos que possuem mais do que a escolaridade requerida é a proporção de sobreeducação dentro da família ocupacional.

Com respeito à determinação da variável escolaridade requerida para as estimações dos coeficientes do modelo, usou-se o seguinte padrão: para os casos em que a escolaridade requerida era única e compreendia um único ano de estudo, este ano era usado na variável como valor desta. Para os casos em que a escolaridade requerida compreendia uma faixa de anos de estudo, o critério adotado foi o da média de anos de estudo da faixa. No exemplo dos Técnicos e Auxiliares de Enfermagem, a variável assume o valor 9,5, que é a média entre 8 e 11 anos de estudo (faixa de escolaridade requerida desta família). No caso da variável escolaridade requerida ser o valor médio, a definição das outras variáveis que dependem desta apresenta a seguinte mudança:

sobreduc $=$ escolar_possuída - máximoescolar_requer, na qual máximoescolar_requer é o maior valor de anos de estudo que a faixa de escolaridade requerida compreende para a família ocupacional. Se escolar _ possuída for maior que máximoescolar_requer, a variável sobreduc é o valor da diferença entre ambas, sendo zero para os demais casos;

subeduc $=$ mínimoescolar_requer - escolar_ possuída, na qual mínimoescolar_requer é o menor valor de anos de estudos que a faixa de escolaridade requerida compreende para a família ocupacional. Se a variável mínimoescolar_requer for maior que a variável escolar _ possuída, a variável subeduc é o valor da diferença entre ambas, sendo zero para os demais casos.

20 É importante notar que, com este procedimento, optamos por uma alternativa conservadora relativamente ao enquadramento na categoria dos sobreeducados na medida em que tende a subestimar sua incidência. Atente, por exemplo, para a situação de um indivíduo que tenha concluído seu curso em oito semestres e depois tenha freqüentado um curso de mestrado por um ano. Este acabará sendo tratado de forma equivalente ao indivíduo que concluiu seu curso em dez semestres. 


\section{RESULTADOS}

\subsection{Incidência de Sobreeducação e Subeducação}

Com relação à incidência da diferença entre escolaridade requerida na família ocupacional e escolaridade possuída pelos indivíduos, são mostradas as taxas para o Brasil, por região e para o Estado de São Paulo de forma agregada. Para o Brasil são mostradas as taxas por grande grupo da CBO 2002. É importante salientar que foi levado em consideração o peso dos indivíduos na amostra do Censo de 2000 para o cálculo das taxas de sobreeducação e subeducação.

\section{TABELA 4 - INCIDÊNCIA DE SOBREEDUCAÇÃO E SUBEDUCAÇÃO}

\begin{tabular}{lccccrrr}
\hline Situação & $\begin{array}{c}\text { São Paulo } \\
\%\end{array}$ & $\begin{array}{c}\text { Sudeste } \\
\%\end{array}$ & $\begin{array}{c}\text { Nordeste } \\
\%\end{array}$ & $\begin{array}{c}\text { Centro- } \\
\text { Oeste } \\
\%\end{array}$ & $\begin{array}{c}\text { Sul } \\
\%\end{array}$ & $\begin{array}{c}\text { Norte } \\
\%\end{array}$ & $\begin{array}{c}\text { Brasil } \\
\%\end{array}$ \\
\hline Adequação & 30,2 & 30,1 & 25,7 & 27,5 & 30 & 28,1 & 28,8 \\
Sobreeducação & 19,8 & 18,5 & 14,7 & 16,2 & 18,6 & 15,7 & 17,3 \\
Subeducação & 49,4 & 50,8 & 58,1 & 55,6 & 50,4 & 55,2 & 53 \\
Não determinado ${ }^{21}$ & 0,5 & 0,5 & 1,5 & 0,7 & 1 & 1,1 & 0,9 \\
Total & 100 & 100 & 100 & 100 & 100 & 100 & 100 \\
\hline
\end{tabular}

A amostra analisada representa um total de 34.333 .747 indivíduos, número obtido ao levar em conta o peso das observações. Os resultados mostram que a subeducação é predominante no mercado de trabalho brasileiro. Para os dados do Brasil, 53\% dos indivíduos nas famílias ocupacionais selecionadas são subeducados. A adequação não chega a $30 \%$ e a sobreeducação é de $17,3 \%$. Estas taxas evidenciam considerável desajuste entre requisitos educacionais dos empregos e a escolaridade dos trabalhadores no Brasil, pois 70,3\% destes não estão adequados com relação à escolaridade requerida nas famílias ocupacionais.

Em termos regionais, observa-se que o Estado de São Paulo possui a mais alta taxa de adequação $(30,2 \%)$, enquanto a região Nordeste, com $25,7 \%$, é a que apresenta a menor adequação entre as regiões brasileiras.

A sobreeducação é maior também no Estado de São Paulo, pois quase $20 \%$ dos indivíduos têm mais escolaridade do que é exigido na ocupação. A região Sul pos-

21 Considerou-se como 'não determinado' as freqüências relativas correspondentes aos valores 20 e 30 da variável Anos de Estudo, que representam no censo, respectivamente, 'não determinado' e 'alfabetização de adultos'. 
sui a maior sobreeducação entre as regiões $(18,6 \%)$, e o Nordeste, a menor taxa $(14,7 \%)$.

A subeducação varia entre 49,4\% no Estado de São Paulo e 58,1\% no Nordeste. Entre as regiões, o Sul e o Sudeste apresentam a menor subeducação - 50,4 e 50,8 por cento, respectivamente.

Portanto, nota-se que as regiões mais desenvolvidas do País - Sudeste e Sul - possuem maior adequação, maior sobreeducação e menor subeducação. As demais regiões tendem a apresentar quadro mais desfavorável do ponto de vista educacional devido às menores taxas de adequação e maiores taxas de subeducação. Particularmente, a região Nordeste apresentou o pior resultado, com adequação de aproximadamente um quarto dos indivíduos e subeducação de quase $60 \%$.

É interessante notar, no entanto, que estes resultados contrastam com aqueles mencionados por McGuinness (2006), sobre análises realizadas em países desenvolvidos em que maior sobreeducação ocorre justamente em mercados de trabalho regionalmente menores. No caso brasileiro, as regiões Sudeste e Sul parecem bem mais próximas do padrão encontrado em países desenvolvidos, enquanto nas demais predomina ainda o problema geral da baixa escolaridade da população.

\section{TABELA 5 - INCIDÊNCIA DE SOBREEDUCAÇÃO E SUBEDUCAÇÃO POR GRANDE GRUPO NO BRASIL}

\begin{tabular}{cccccc}
\hline $\begin{array}{c}\text { Grande } \\
\text { Grupo }\end{array}$ & $\begin{array}{c}\text { Adequação } \\
\%\end{array}$ & $\begin{array}{c}\text { Sobreeducação } \\
\%\end{array}$ & $\begin{array}{c}\text { Subeducação } \\
\%\end{array}$ & $\begin{array}{c}\text { Não determinado } \\
\%\end{array}$ & $\begin{array}{c}\text { Total } \\
\%\end{array}$ \\
\hline 2 & 63,0 & 5,5 & 31,1 & 0,3 & 100 \\
3 & 54,7 & 19,2 & 25,5 & 0,7 & 100 \\
4 & 46,5 & 18,9 & 34,1 & 0,5 & 100 \\
5 & 17,6 & 17,0 & 64,4 & 1,0 & 100 \\
6 & 41,7 & 5,9 & 51,1 & 1,3 & 100 \\
7 & 18,7 & 20,0 & 60,5 & 0,9 & 100 \\
8 & 13,8 & 25,0 & 59,9 & 1,2 & 100 \\
9 & 16,7 & 21,6 & 60,8 & 0,8 & 100 \\
\hline
\end{tabular}

Comparando as taxas de adequação entre os grandes grupos, nota-se que o grande grupo 2 apresenta a maior proporção de ocupados que possuem a escolaridade requerida na família ocupacional (63\%) enquanto, com menor adequação, o grande grupo 8 aparece com apenas $13,8 \%$. Com respeito à sobreeducação, os grandes grupos 8 e 9 possuem as maiores taxas, $25 \%$ e 21,6 , respectivamente, enquanto os grandes grupos 2 e 6 apresentaram os menores percentuais, $5,5 \%$ e $5,9 \%$, respectivamente. 
Quanto à subeducação, nota-se que no grande grupo 5 se encontra a maior proporção de trabalhadores com déficit de educação em relação à escolaridade exigida no emprego $(64,4 \%)$.Verifica-se que há a menor taxa de subeducação no grande grupo $3(25,5 \%)$.

Dessa forma, observa-se que os grandes grupos com famílias ocupacionais que apresentam maiores níveis de escolaridade requerida mostraram maiores taxas de adequação. Esse é o caso dos grandes grupos 2, 3 e 4. De outro lado, os grandes grupos cujas famílias ocupacionais exigem menores níveis de escolaridade evidenciaram menores taxas de adequação - grandes grupos $5,7,8$ e 9 . O grande grupo 2, que engloba as famílias ocupacionais que exigem nível superior, apresentou a maior adequação - quase dois terços dos ocupados - o que deve estar ligado às características mais específicas das famílias ocupacionais, reduzindo a existência de subeducação.

Para a sobreeducação, nota-se que no grande grupo 2 esta é reduzida, o que deve ser atribuído aos altos níveis de exigência de escolaridade das famílias ocupacionais, posto que a frequiência de indivíduos tende a ser menor nos mais altos níveis de escolaridade. No grande grupo 3, que relaciona as ocupações dos técnicos de nível médio, cerca de $20 \%$ dos ocupados são sobreeducados. Esses indivíduos são, na maioria, graduados ou com nível superior incompleto.

A subeducação é de aproximadamente $60 \%$ nos grandes grupos 7,8 e 9 , chegando a quase $65 \%$ no grande grupo 5 . Assim como no caso da adequação, parece haver uma relação entre os níveis de escolaridade exigida no grande grupo e as taxas de subeducação, todavia de forma inversa. Quanto maiores os níveis de escolaridade requerida no grande grupo, menor tende a ser a subeducação - este é o caso dos grandes grupos 2, 3 e 4 . De outro lado, quanto menores os níveis, maior tende a ser a subeducação - grandes grupos $5,7,8$ e 9 .

\subsection{Efeitos sobre os Rendimentos}

Por meio da função de rendimentos ORU, foram calculados os impactos da sobre e subeducação no Brasil, nas regiões e no Estado de São Paulo. Também aqui é necessário dizer que as estimações levaram em consideração o peso dos indivíduos na amostra do Censo de 2000.

Para o Brasil, os resultados baseiam-se num total de 33.259.186 indivíduos. Para esses, os retornos da escolaridade possuída, obtidos pela função de rendimentos de Mincer (1974), são de 13\%. Além disso, há uma diferença de rendimentos entre homens e mulheres, com as últimas recebendo $33 \%$ a menos que os homens, ceteris 
paribus. Em virtude dessa diferença, os retornos do modelo ORU são mostrados separadamente para homens e mulheres.

TABELA 6 - RETORNOS DO MODELO ORU E DE MINCER NO BR ASIL

\begin{tabular}{lcc|lcc}
\hline & Especificação: ORU & \multicolumn{3}{c}{ Especificação: Mincer } \\
\hline Variáveis & Homens & Mulheres & Variáveis & Homens & Mulheres \\
\hline Escolar_requer & 0,162 & 0,180 & Anos de estudo & 0,126 & 0,135 \\
& $(2.661,099)$ & $(2.378,714)$ & & $(3009,022)$ & $(2.931,721)$ \\
Sobreduc & 0,121 & 0,139 & & & \\
& $(944,001)$ & $(931,750)$ & & & \\
Subeduc & $-0,101$ & $-0,091$ & & & \\
& $(-1.516,969)$ & $(-1.077,797)$ & & & \\
Idade & 0,081 & 0,064 & Idade & $(1209,982)$ & $(856,700)$ \\
& $(1.177,612)$ & $(854,923)$ & & $-0,001$ & $-0,001$ \\
Idade_quad & $-0,001$ & $-0,001$ & Idade_quad & $(-881,802)$ & $(-535,239)$ \\
& $(-874,131)$ & $(-548,180)$ & & 19.177 .754 & 14.081 .432 \\
$N$ & 19.177 .754 & 14.081 .432 & $N$ & 0,388 & 0,429 \\
\hline$R^{2}$ ajustado & 0,402 & 0,449 & $R^{2}$ ajustado & 0,065 \\
\hline
\end{tabular}

Obs: Estatística $t$ entre parênteses; todos os coeficientes são significativos a $1 \%$.

A Tabela 6 traz os resultados das estimações para o Brasil e permite a comparação dos retornos do modelo adotado neste estudo com aqueles oriundos da função de rendimentos minceriana. Observa-se que os retornos da escolaridade requerida são maiores que os retornos da escolaridade possuída pelo indivíduo, tanto para homens como para mulheres. Para os homens, cada ano de escolaridade requerida na ocupação resulta em um acréscimo nos rendimentos de 16,2\%, enquanto o retorno da escolaridade possuída é de $12,6 \%$. Para as mulheres, o retorno da escolaridade requerida é superior ao dos homens (18\%). O retorno da escolaridade possuída para as mulheres $(13,5 \%)$ também é maior do que para os homens.

Os retornos da escolaridade requerida são maiores, em módulo, que os retornos da sobre e subeducação, para homens e mulheres. Os retornos da sobreeducação, por sua vez, são maiores que os retornos da subeducação, em módulo, para ambos os gêneros. O retorno da sobreeducação no Brasil é cerca de três quartos do retorno da escolaridade requerida, para homens e mulheres, o que mostra um maior incentivo para ser sobreeducado no Brasil relativamente a outros países, nos quais esta razão varia entre metade a dois terços (HARTOG, 2000). Esse padrão de comparação dos coeficientes está em linha com as regularidades dos demais estudos na área, de forma que os dados brasileiros fornecem evidência adicional para a literatura. 
Comparando os retornos da sobreeducação, nota-se que as mulheres obtêm um acréscimo superior ao dos homens por cada ano de estudo a mais do que é exigido na ocupação - $13,9 \%$ contra $12,1 \%$, respectivamente. Quanto à subeducação, os homens são mais penalizados que as mulheres. Enquanto o subeducado tem seus rendimentos reduzidos em $10,1 \%$ por cada ano de estudo a menos do que é exigido na ocupação, a subeducada tem uma redução de $9,1 \%$.

\begin{tabular}{|c|c|c|c|c|c|c|}
\hline \multirow[t]{2}{*}{$\begin{array}{l}\text { Grande } \\
\text { grupo }\end{array}$} & Escolar_requer & Sobreduc & Subeduc & Escolar_requer & Sobreduc & Subeduc \\
\hline & \multicolumn{3}{|c|}{ Homens } & \multicolumn{3}{|c|}{ Mulheres } \\
\hline 2 & $\begin{array}{c}0,464 \\
(290,884)\end{array}$ & $\begin{array}{c}0,239 \\
(72,967)\end{array}$ & $\begin{array}{c}-0,109 \\
(-321,687)\end{array}$ & $\begin{array}{c}0,571 \\
(412,983)\end{array}$ & $\begin{array}{c}0,187 \\
(82,252)\end{array}$ & $\begin{array}{c}-0,118 \\
(-376,452)\end{array}$ \\
\hline 3 & $\begin{array}{c}0,124 \\
(203,012)\end{array}$ & $\begin{array}{c}0,138 \\
(288,238)\end{array}$ & $\begin{array}{c}-0,112 \\
(-485,901)\end{array}$ & $\begin{array}{c}0,129 \\
(305,133)\end{array}$ & $\begin{array}{c}0,143 \\
(424,101)\end{array}$ & $\begin{array}{c}-0,109 \\
(-389,963)\end{array}$ \\
\hline 4 & $\begin{array}{c}0,092 \\
(311,457)\end{array}$ & $\begin{array}{c}0,127 \\
(284,018)\end{array}$ & $\begin{array}{c}-0,074 \\
(-316,798)\end{array}$ & $\begin{array}{c}0,016 \\
(27,456)\end{array}$ & $\begin{array}{c}0,158 \\
(408,508)\end{array}$ & $\begin{array}{c}-0,064 \\
(-263,355)\end{array}$ \\
\hline 5 & $\begin{array}{c}0,113 \\
(745,259)\end{array}$ & $\begin{array}{c}0,120 \\
(504,656)\end{array}$ & $\begin{array}{c}-0,089 \\
(-694,973)\end{array}$ & $\begin{array}{c}0,092 \\
(576,397)\end{array}$ & $\begin{array}{c}0,116 \\
(579,970)\end{array}$ & $\begin{array}{c}-0,066 \\
(-581,261)\end{array}$ \\
\hline 6 & $\begin{array}{l}- \\
-\end{array}$ & $\begin{array}{c}0,123 \\
(99,478)\end{array}$ & $\begin{array}{c}-0,079 \\
(-185,092)\end{array}$ & $\begin{array}{l}- \\
-\end{array}$ & $\begin{array}{c}0,139 \\
(36,300)\end{array}$ & $\begin{array}{c}-0,120 \\
(-42,120)\end{array}$ \\
\hline 7 & $\begin{array}{c}0,113 \\
(686,467)\end{array}$ & $\begin{array}{c}0,097 \\
(512,725)\end{array}$ & $\begin{array}{c}-0,069 \\
(-571,496)\end{array}$ & $\begin{array}{c}0,063 \\
(70,668)\end{array}$ & $\begin{array}{c}0,072 \\
(140,420)\end{array}$ & $\begin{array}{c}-0,061 \\
(-191,461)\end{array}$ \\
\hline 8 & $\begin{array}{c}0,070 \\
(79,433)\end{array}$ & $\begin{array}{c}0,074 \\
(102,178)\end{array}$ & $\begin{array}{c}-0,066 \\
(-161,066)\end{array}$ & $\begin{array}{c}0,117 \\
(97,866)\end{array}$ & $\begin{array}{c}0,082 \\
(73,966)\end{array}$ & $\begin{array}{c}-0,070 \\
(-79,275)\end{array}$ \\
\hline 9 & $\begin{array}{c}0,136 \\
(347,402)\end{array}$ & $\begin{array}{c}0,087 \\
(156,779)\end{array}$ & $\begin{array}{c}-0,087 \\
(-304,520)\end{array}$ & $\begin{array}{c}0,131 \\
(26,803)\end{array}$ & $\begin{array}{c}0,093 \\
(18,953)\end{array}$ & $\begin{array}{c}-0,090 \\
(-23,995)\end{array}$ \\
\hline
\end{tabular}

Obs: Estatística $t$ entre parênteses; todos os coeficientes são significativos a $1 \%$.

$\mathrm{Na}$ análise por grande grupo para o Brasil, nota-se que grande grupo 2 apresenta maiores retornos para escolaridade requerida, comparativamente à sobreeducação e para o módulo do coeficiente da subeducação, para homens e mulheres. Comparando os gêneros, observa-se que as mulheres apresentam maiores coeficientes para a escolaridade requerida - $57,1 \%$ contra $46,4 \%$ para os homens -, enquanto os homens possuem maiores retornos da sobreeducação $-23,9 \%$ contra $18,7 \%$ para as mulheres. Já a subeducação penaliza mais as mulheres $(-11,8 \%)$ do que os homens $(-10,9 \%)$. Esse grande grupo caracteriza-se por coeficientes muito elevados para escolaridade requerida e sobreeducação, sinalizando maiores recompensas para a formação de 
nível superior, que é a escolaridade requerida das famílias ocupacionais do grande grupo $2 .^{22}$

No grande grupo 3, relativo aos técnicos de nível médio, verifica-se um resultado surpreendente comparativamente ao padrão internacional. $\mathrm{O}$ retorno da escolaridade requerida é menor que o da sobreeducação para ambos os gêneros - 12,4\% contra $13,8 \%$ para os homens e $12,9 \%$ contra $14,3 \%$ para as mulheres. O retorno da subeducação é menor, em módulo, que os retornos da escolaridade requerida e da sobreeducação. Enquanto as mulheres são mais recompensadas com relação à escolaridade requerida e à sobreeducação, os homens são mais penalizados no caso de subeducação (-11,2\% contra $-10,9 \%$ para as mulheres). Nesse grande grupo, há incentivos para a sobreeducação, visto que o retorno para cada ano em adição à escolaridade exigida no emprego é maior do que o retorno para cada ano de estudo exigido. Como a sobreeducação, no grande grupo 3, é de pessoas que possuem nível superior incompleto ou completo, conclui-se que há incentivos para esta formação para os indivíduos nas famílias ocupacionais dos técnicos de nível médio.

Também no grande grupo 4, relativo ao grande grupo dos trabalhadores de serviços administrativos, repete-se o resultado inesperado encontrado no grande grupo 3, com retorno da sobreeducação superior ao retorno da escolaridade requerida, para homens e mulheres. É interessante notar também que, para as mulheres, o retorno da escolaridade requerida é bastante reduzido (1,6\%), em contraste com o da sobreeducação $(15,8 \%)$. Conclui-se que há incentivos para ser sobreeducado neste grupo e que esse benefício é maior para as mulheres.

Para o grande grupo 5 (trabalhadores dos serviços, vendedores do comércio em lojas e mercados) verifica-se uma pequena diferença, no caso dos homens, para os quais o retorno da escolaridade requerida é $11,3 \%$ contra $12 \%$ da sobreeducação e o retorno da subeducação é -8,9\%. Para as mulheres, esses coeficientes são, respectivamente: $9,2 \%, 11,6 \%$ e $-6,6 \%$. Dessa forma, observa-se que os homens são mais recompensados do que as mulheres nas situações de adequação e sobreeducação, bem como perdem mais quando são subeducados neste grande grupo.

No grande grupo 6, são observados apenas os retornos da sobre e subeducação, pois há somente uma família ocupacional, de modo que a variável escolaridade requerida assume um único valor, não podendo, portanto, ser estimado o retorno desta. Os resultados mostram que as mulheres apresentam maiores coeficientes, em módulo,

22 Resultados obtidos por Ferreira (2004) confirmam o grande diferencial de remuneração existente no final da década de 90, mais precisamente em 1998, entre um trabalhador do sexo masculino com ensino superior e aquele apenas com ensino médio. $\mathrm{O}$ autor encontrou, em média, uma diferença de 2,3 vezes favorável ao graduado. 
para a sobre e subeducação - $13,9 \%$ e $12 \%$ contra $12,3 \%$ e $7,9 \%$ para os homens, respectivamente.

O retorno da escolaridade requerida para os homens no grande grupo 7 é 11,3\%, maior que o retorno da sobreeducação $(9,7 \%)$. O retorno da subeducação é $-6,9 \%$. Para as mulheres, o retorno da escolaridade requerida $(6,3 \%)$ é menor que o retorno da sobreeducação $(7,2 \%)$, porém maior que o da subeducação em módulo $(6,1 \%)$.

No grande grupo 8, o retorno da escolaridade requerida é $7 \%$, da sobreeducação é $7,4 \%$ e o da subeducação é $-6,6 \%$ para os homens. Já para as mulheres, na mesma ordem, os valores são: $11,7 \%, 8,2 \%$ e $-7 \%$. Assim, os homens possuem um retorno da escolaridade em excesso um pouco superior ao retorno da escolaridade requerida. As mulheres, contudo, possuem retorno da escolaridade requerida significativamente maior que o da sobreeducação, evidenciando recompensas maiores para a escolaridade exigida na ocupação. Os grandes grupos 7 e 8 reúnem os trabalhadores da produção de bens e serviços industriais.

Os resultados para o último grande grupo (dos trabalhadores de reparação e manutenção) apresentam o padrão internacional, tanto entre homens como entre mulheres, ou seja, retornos da escolaridade requerida maiores que os da sobreeducação e da subeducação, em módulo.

É interessante notar que o padrão verificado na análise dos dados agregados do Brasil confirma as regularidades identificadas por Hartog (2000), porém, não se repete em todos os grandes grupos. De fato, apenas o grande grupo 2 apresentou padrão idêntico ao nacional, tanto para homens como mulheres. Nos demais, quando observado, ocorria para apenas um dos gêneros. Além disso, merecem destaque os incentivos para a sobreeducação encontrados nos grandes grupos 3, 4 e $5 \mathrm{em}$ ambos os gêneros. A subeducação não apresentou coeficientes, em módulo, maiores que os da sobreeducação. 
TABELA 8 - RETORNOS DO MODELO ORU PARA HOMENS - DESAGREGAÇÃO REGIONAL

\begin{tabular}{lcccccc}
\hline Variáveis & São Paulo & Sudeste & Nordeste & Centro-Oeste & Sul & Norte \\
\hline Escolar_requer & 0,152 & 0,160 & 0,149 & 0,171 & 0,154 & 0,139 \\
& $(1.378,731)$ & $(1.924,107)$ & $(1.081,996)$ & $(818,835)$ & $(1.048,567)$ & $(535,126)$ \\
Sobreduc & 0,112 & 0,124 & 0,111 & 0,127 & 0,114 & 0,102 \\
& $(518,235)$ & $(729,837)$ & $(365,187)$ & $(263,547)$ & $(380,266)$ & $(181,221)$ \\
Subeduc & $-0,087$ & $-0,090$ & $-0,098$ & $-0,095$ & $-0,088$ & $-0,087$ \\
& $(-683,128)$ & $(-942,291)$ & $(-721,656)$ & $(-407,509)$ & $(-520,321)$ & $(-328,078)$ \\
Idade & 0,083 & 0,080 & 0,076 & 0,086 & 0,083 & 0,087 \\
& $(663,681)$ & $(846,247)$ & $(500,655)$ & $(364,215)$ & $(503,251)$ & $(299,324)$ \\
Idade_quad & $-0,001$ & $-0,001$ & $-0,001$ & $-0,001$ & $-0,001$ & $-0,001$ \\
& $(-497,828)$ & $(-629,195)$ & $(-373,569)$ & $(-284,085)$ & $(-379,260)$ & $(-230,704)$ \\
$N$ & 5.047 .721 & 9.402 .514 & 4.030 .531 & 1.523 .422 & 3.050 .538 & 1.170 .748 \\
$R^{2}$ ajustado & 0,406 & 0,410 & 0,357 & 0,422 & 0,385 & 0,323 \\
\hline
\end{tabular}

Obs: Estatística $t$ entre parênteses; todos os coeficientes são significativos a $1 \%$.

Em termos geográficos e com distinção de gênero, tanto considerando apenas o Estado de São Paulo, como cada uma das regiões brasileiras (Tabela 8 e Tabela 9), observa-se a confirmação das regularidades (retorno para cada ano da escolaridade requerida maior que o retorno por ano da sobre e da subeducação, em módulo e retornos da sobreeducação superiores aos da subeducação, também em módulo) encontradas na análise dos dados nacionais e mencionadas por Hartog (2000).

TABELA 9 - RETORNOS DO MODELO ORU PARA MULHERES - DESAGREGAÇÃO REGIONAL

\begin{tabular}{lcccccc}
\hline Variáveis & São Paulo & Sudeste & Nordeste & Centro-Oeste & Sul & Norte \\
\hline Escolar_requer & 0,174 & 0,181 & 0,173 & 0,184 & 0,165 & 0,175 \\
& $(1298,025)$ & $(1.754,601)$ & $(1.041,491)$ & $(685,051)$ & $(971,290)$ & $(504,975)$ \\
Sobreduc & 0,124 & 0,136 & 0,147 & 0,152 & 0,121 & 0,145 \\
& $(477,796)$ & $(669,348)$ & $(442,179)$ & $(286,306)$ & $(368,174)$ & $(206,902)$ \\
Subeduc & $-0,074$ & $-0,081$ & $-0,099$ & $-0,093$ & $-0,077$ & $-0,095$ \\
& $(-460,946)$ & $(-664,510)$ & $(-593,908)$ & $(-305,460)$ & $(-376,139)$ & $(-274,377)$ \\
Idade & 0,062 & 0,064 & 0,060 & 0,060 & 0,060 & 0,062 \\
& $(467,356)$ & $(625,856)$ & $(377,961)$ & $(226,799)$ & $(338,232)$ & $(190,969)$ \\
Idade_quad & $-0,001$ & $-0,001$ & 0,000 & 0,000 & $-0,001$ & $-0,001$ \\
& $(-313,625)$ & $(-412,390)$ & $(-235,912)$ & $(-139,568)$ & $(-231,520)$ & $(-118,230)$ \\
$N$ & 3.563 .511 & 6.794 .092 & 3.137 .062 & 1.090 .263 & 2.252 .391 & 807.626 \\
$R^{2}$ ajustado & 0,447 & 0,455 & 0,454 & 0,466 & 0,429 & 0,410 \\
\hline
\end{tabular}

Obs: Estatística $t$ entre parênteses; todos os coeficientes são significativos a $1 \%$. 
Comparando os retornos entre os gêneros nas regiões, verifica-se que os retornos da escolaridade requerida são maiores para as mulheres, bem como os da sobreeducação, evidenciando um maior incentivo tanto para possuir a escolaridade requerida no emprego, como para possuir anos em excesso de estudo para as mulheres no mercado de trabalho brasileiro. Para a subeducação, os homens apresentaram maiores reduções nos retornos nas regiões Sudeste, Centro-Oeste e Sul. Além disso, as mulheres tendem a apresentar uma razão entre os coeficientes da sobreeducação e escolaridade requerida maior que a dos homens nas regiões.

\section{CONSIDERAÇÕES FINAIS}

Este artigo buscou, por um lado, acrescentar evidências à literatura da sobreeducação e subeducação, avaliando para o caso brasileiro a incidência e os efeitos sobre os rendimentos da diferença entre escolaridade requerida na ocupação e escolaridade possuída pelo indivíduo, especialmente com desagregação regional, por grande grupo de ocupação e por gênero.

Em relação à incidência, conforme esperado, verificou-se que as taxas de subeducação encontradas chamam a atenção para uma situação bastante conhecida, que são os baixos níveis de escolaridade da população. Para o Brasil, os subeducados são 53\%, os adequados representam $28,8 \%$ e os sobreeducados são $17,3 \%$ dos indivíduos ocupados. Entre as regiões, os níveis de adequação oscilam entre 25 e 31 por cento e os de sobreeducação entre 14 e 19 por cento. As regiões Sudeste e Sul apresentam resultados um pouco melhores aos apresentados pelas demais regiões. O Nordeste apresenta a mais alta subeducação, quase $60 \%$ dos trabalhadores analisados são subeducados para seus empregos.

Com relação às taxas por grande grupo ocupacional, para aqueles com maiores níveis de escolaridade requerida (2, 3 e 4$)$, as taxas de adequação são superiores e a subeducação é menor. Já para os grandes grupos que englobam as famílias ocupacionais com menores níveis de escolaridade requerida $(5,7,8$ e 9), as taxas de adequação foram muito pequenas, não alcançando $20 \%$, e as taxas de subeducação são as mais expressivas.

Sobre os impactos nos rendimentos para o Brasil, conclui-se que os retornos da escolaridade requerida são maiores que os retornos da escolaridade possuída pelo indivíduo. Além disso, para o Brasil e as regiões destacadas, os retornos da escolaridade requerida são maiores que os retornos da sobreeducação e maiores que o módulo dos retornos da subeducação. Por sua vez, os retornos da sobreeducação são maiores que 
o módulo dos retornos da subeducação. Estes resultados confirmam o padrão das regularidades mencionadas na seção introdutória, discutidas em Hartog (2000).

Em uma comparação sobre resultados produzidos para diversos países, Groot e Maassen van den Brink (2000) agrupam 25 estudos, nos quais obtêm 50 estimativas da incidência de sobreeducação e 36 de subeducação, encontrando uma média não-ponderada de $23,3 \%$ para a sobreeducação e desvio padrão de $9,9 \%$. Para a subeducação estes valores são $14,4 \%$ e $8,2 \%$, respectivamente. ${ }^{23}$

Os resultados das estimações no Brasil também podem ser comparados à metaanálise realizada por Rubb (2003). As médias não-ponderadas dos coeficientes da escolaridade requerida, sobreeducação e subeducação da função de rendimentos ORU, para as 85 estimativas agrupadas, são 9,6, 5,2 e - 4,8 por cento, respectivamente. Para dados de homens no Brasil, estes coeficientes são, na mesma ordem, 16,2, 12,1 e $-10,1$ por cento.

Conforme mencionado anteriormente, há uma escassez de estudos dessa natureza em países em desenvolvimento. Quinn e Rubb (2006), analisando dados mexicanos, é uma exceção. A Tabela 10 mostra resultados das taxas de sobreeducação e subeducação obtidas no referido artigo. Deve-se notar que este trabalho utiliza três métodos para determinação da escolaridade requerida - média, moda e uma definição que utiliza o método de mínimos quadrados ordinários (OLS). Apesar de algumas diferenças metodológicas, a comparação com os resultados encontrados para o Brasil é interessante. Por um lado, verifica-se que a subeducação no México é bem menos expressiva, principalmente para as definições de escolaridade requerida a partir da média e OLS. As taxas de sobreeducação são similares às do Brasil para estas duas definições. Já para a moda, as taxas de sobreeducação no México são consideravelmente maiores que as do Brasil.

23 Nesta meta-análise são agrupados resultados de estudos que utilizam métodos distintos para o cálculo da escolaridade requerida, incluindo o método aqui adotado. 
TABELA 10 - INCIDÊNCIA E RETORNOS DA SOBREEDUCAÇÃO E SUBEDUCAÇÃO - HOMENS NO MÉXICO

\begin{tabular}{|c|c|c|c|}
\hline \multicolumn{4}{|c|}{ Incidência } \\
\hline 1987-1999 & Média & Moda & OLS \\
\hline Sobreeducados & 17,2 & 39,9 & 13,5 \\
\hline Subeducados & 19,4 & 30,9 & 13,8 \\
\hline \multicolumn{4}{|c|}{ Retornos } \\
\hline Sobreeducação & 0,043 & 0,048 & 0,049 \\
\hline Escolaridade requerida & 0,085 & 0,076 & 0,090 \\
\hline Subeducação & $-0,030$ & $-0,036$ & $-0,039$ \\
\hline
\end{tabular}

Nota: ${ }^{a}$ Quinn e Rubb (2006).

Relativamente aos retornos, conclui-se que os coeficientes produzidos nas nossas estimativas são superiores aos mexicanos e aos apresentados na meta-análise, evidenciando para o Brasil retornos sobre os rendimentos maiores da escolaridade requerida e da sobreeducação, além de reduções maiores nos retornos para a subeducação em comparação com outros países.

É interessante notar, no entanto, que a análise realizada por grande grupo ocupacional evidenciou algumas peculiaridades relativas a algumas categorias. Em termos gerais, pode-se afirmar que apesar de os padrões de sinais repetirem os resultados internacionais, a ordenação de magnitudes dos coeficientes da escolaridade requerida, da sobreeducação e subeducação não se mantém na forma em que aparecem para os dados agregados na maioria dos grandes grupos. Especialmente, merecem destaque as evidências encontradas para os grandes grupos 3 e 4, relativos aos técnicos de nível médio e dos trabalhadores de serviços administrativos, respectivamente. Em ambos o retorno da escolaridade requerida é menor que o da sobreeducação para ambos os gêneros. Nesses grandes grupos, há incentivos para a sobreeducação, visto que o retorno para cada ano adicional à escolaridade exigida no emprego é maior do que o retorno para cada ano de estudo exigido.

Finalmente, relativamente às causas da sobreeducação, merecem destaque as observações apresentadas por Green et al. (2002) acerca das evidências de que baixo desempenho em testes de matemática realizados aos 16 anos no Reino Unido aumenta a probabilidade de o indivíduo tornar-se sobreeducado ao longo da vida profissional. Os autores levantam a hipótese de que os indivíduos seriam teoricamente sobreeducados na medida em que sua escolaridade excederia aquela requerida para o desempenho de suas atividades; porém, isto, na verdade, se deveria ao fato de que seus conhecimentos e habilidades não atenderiam às necessidades de trabalhos compatíveis com os anos de estudo freqüentados. Assim, concretamente, estes indi- 
víduos não seriam sobreeducados, mas apenas estariam desempenhando atividades adequadas a seus efetivos conhecimentos e competências.

No caso brasileiro, esta é uma hipótese bastante plausível, na medida em que a baixa qualidade do ensino básico é amplamente comprovada nos resultados obtidos por nossos estudantes nas várias avaliações educacionais de caráter nacional. É ilustrativo mencionar o desempenho de nossos estudantes no exame PISA (Programa Internacional para Avaliação de Alunos) realizado em 2003: na escala geral de matemática, metade dos alunos brasileiros estão abaixo do nível $1^{24}$ (analfabetismo funcional), $43 \%$ estão entre os níveis 1 e 3 (entre muito fraco e fraco) e apenas 4\% estão entre os níveis 4 e 6 . A se comprovar a causalidade entre baixo desempenho escolar, especialmente em matemática, e sobreeducação no futuro do indivíduo também no Brasil - o que foge do escopo deste trabalho-, reforçam-se os argumentos acerca da necessidade urgente de reformulação do nosso sistema educacional que vise reduzir o enorme descompasso existente entre o que é ensinado nas nossas escolas e o que é demandado pela sociedade e pelo mercado de trabalho.

Na mesma linha, porém com um foco mais direcionado ao ensino superior, é interessante notar a preocupação de McGuinness (2006) em relação à política australiana de perseguir a meta de participação no ensino superior de $50 \%$ da população na faixa etária correspondente. Ao mencionar resultados recentes relativos ao Reino Unido, indica que após período de estímulo à expansão do ensino superior, a incidência de sobreeducação aumentou, em especial nas áreas de Artes e Humanidades. O autor justifica seu ponto de vista mencionando que a literatura sobre o tema da sobreeducação, especialmente em relação ao ensino superior, evidencia o fato de que a incidência da sobreeducação não é aleatória, afetando particularmente os indivíduos formados nas áreas de Artes, Humanidades e algumas Ciências Sociais.

Também verificamos no Brasil uma grande ênfase na perseguição de metas relativas ao ingresso no ensino superior, inclusive com destaque dado pelo Ministério da Educação ao ProUni - Programa Universidade para Todos, que foi criado pela MP $\mathrm{n}^{\mathrm{o}} 213 / 2004$ e institucionalizado pela Lei $\mathrm{n}^{\circ} 11.096$, de 13 de janeiro de 2005, cuja finalidade é a concessão de bolsas de estudos integrais e parciais a estudantes de baixa renda, em cursos de graduação e seqüenciais de formação específica. Ainda, segundo informações obtidas na página do programa: ${ }^{25}$

No seu primeiro processo seletivo, o ProUni oferecen 112 mil bolsas em 1.142 instituições de ensino superior de todo o Pais. Nos próximos quatro

24 O desempenho de cada um dos alunos é classificado em seis níveis de competência, sendo 1, o mais baixo, considerado muito fraco, e o 6 , o excelente.

25 O link é http://prouni-inscricao.mec.gov.br/prouni/Oprograma.shtm [download realizado em 21/04/2007]. 
anos, o programa deverá oferecer 400 mil novas bolsas de estudos(...) Todas estas ações vão ao encontro das metas do Plano Nacional de Educação, que prevê a presença, até 2010, de pelo menos 30\% da população na faixa etária de 18 a 24 anos na educação superior, hoje restrita a $10,4 \%$.

Deve-se notar que dados de novembro de 2006 indicam que das 108 mil bolsas do programa, aproximadamente $50 \%$ destinaram-se às áreas de ciências sociais, negócios e direito, pouco mais de 7,2\% para as áreas de ciências, matemática e computação, aproximadamente 5,5\% para engenharia, produção e construção e menos de $1 \%$ para agricultura e veterinária. Deste modo, apesar de méritos apresentados pelo programa, inclusive de contemplar uma análise acerca do desempenho acadêmico dos beneficiários comparativamente aos não-beneficiários ${ }^{26}$, é razão de preocupação a falta de um componente de avaliação ${ }^{27}$ acerca das efetivas possibilidades de inserção no mercado de trabalho dos beneficiários de acordo com a área de formação, cujas informações possam ser amplamente divulgadas de modo a facilitar escolhas mais fundamentadas.

\section{REFERENCIAS}

BRASIL. INSTITUTO BRASILEIRO DE GEOGRAFIA E ESTATÍSTICA. Censo, 2000.

BRASIL. MINISTÉRIO DA EDUCAÇÃO. Instituto Nacional de Estudos e Pesquisas Educacionais Anísio Teixeira (INEP).

BRASIL. MINISTÉRIO DO TRABALHO E EMPREGO. Classificação Brasileira das Ocupações de 2002 (livros 1 e 2), 2002.

BÜCHEL, F.; MERTENS, A. Overeducation, undereducation, and the theory of career mobility. Applied Economics, v. 36, n. 8, p. 803-816, 2004.

DUNCAN, G.; HOFFMAN, S.D. The incidence and wage effects of overeducation. Economics of Education Review, v. 1, n. 1, p. 75-86, 1981.

FERREIRA, S.G. The provision of education and its impacts on College Premium in Brazil. Revista Brasileira de Economia, v. 58, n. 2, p. 211-233, 2004.

26 Os resultados da análise comparativa podem ser encontrados em http://portal.mec.gov.br/arquivos/ pdf/tabela_prouni_10_04_2007.pdf [download realizado em 21/04/2007]. Infelizmente, não foram divulgados até esta data detalhes acerca da metodologia aplicada nesta análise comparativa. Porém, dadas as características do ENADE que é aplicado a alunos de primeiro e do último ano do curso, é de se supor que este acompanhamento se limitará a apenas estes dois momentos do percurso acadêmico dos beneficiários.

27 Por exemplo, nos Estados Unidos o Bureau of Labor Statistics é responsável pela publicação do Occupational Outlook Handbook, uma fonte de informações sobre as carreiras, revisada a cada dois anos, e que contém dados sobre escolaridade requerida, remuneração, perspectivas profissionais, condiçóes de trabalho etc. Maiores informações podem ser obtidas em http://www.bls.gov/oco/home.htm. 
FUVEST. Manual do Candidato, 2000.

GREEN, F; MCINTOSH, S.; VIGNOLES, A. The utilization of education and skills: evidence from Britain. Manchester School, v. 70 n.6, p. 792-811, 2002.

GROOT, W.; MAASSEN VAN DEN BRINK, H. Overeducation in the labor market: a meta-analysis. Economics of Education Review, v. 19, n. 2, p. 149-158, 2000.

HARTOG, J. Over-education and earnings: where are we, where should we go? Economics of Education Review, v. 19, n. 2, p. 131-147, 2000.

MCGUINNESS, S. Overeducation in the Labour Market. Journal of Economic Surveys, v. 20, n. 3, p. 387-418, 2006.

; BENNETT, J. Overeducation in the graduate labour market: a quantile regression approach. Economics of Education Review, 2006. In press.

MINCER, J. Schooling, experience, and wages. New York: National Bureau of Economic Research, 1974.

QUINN, M.A.; RUBB, S. Mexico's labor market: the importance of educationoccupation matching on wages and productivity in developing countries. Economics of Education Review, v. 25, n. 2, p. 147-156, 2006.

RUBB, S. Overeducaton in the labour market: a comment and re-analysis of a metaanalysis. Economics of Education Review, v. 22, n. 6, p. 621-629, 2003.

. Overeducation, undereducation, and the theory of career mobility: a comment and a note on underemployment. Applied Economics Letters, v. 12, n. 2, p. 115-118, 2005.

RUMBERGER, R.W. The impact of surplus schooling on productivity and earnings. Journal of Human Resources, v. 22, n. 1, p. 24-50, 1987.

SANTOS, A.M. Overeducation no mercado de trabalho brasileiro. Revista Brasileira de Economia de Empresas, v. 2, n. 2, p. 1-22, 2002.

SCHWARTZMAN, S. Equity, quality and relevance in higher education in Brazil. Anais da Academia Brasileira de Ciências, v. 76, n. 1, p. 173-188, 2004.

SICHERMAN, N. Overeducation in the labor market. Journal of Labor Economics, v. 9, n. 2, p. 101-122, 1991.

VERHAEST, D.; OMEY, E. Discriminating between alternative measures of overeducation. Applied Economics, v. 38, n. 18, p. 2113-2120, 2006. 